\title{
REVIEW
}

\section{How to assess prognosis after cardiac arrest and therapeutic hypothermia}

\author{
Fabio Silvio Taccone ${ }^{1 *}$, Tobias Cronberg ${ }^{2}$, Hans Friberg ${ }^{3}$, David Greer ${ }^{4}$, Janneke Horn ${ }^{5}$, Mauro Oddo ${ }^{6}$, \\ Sabino Scolletta ${ }^{7}$ and Jean-Louis Vincent ${ }^{1}$
}

\begin{abstract}
The prognosis of patients who are admitted in a comatose state following successful resuscitation after cardiac arrest remains uncertain. Although the introduction of therapeutic hypothermia (TH) and improvements in postresuscitation care have significantly increased the number of patients who are discharged home with minimal brain damage, short-term assessment of neurological outcome remains a challenge. The need for early and accurate prognostic predictors is crucial, especially since sedation and TH may alter the neurological examination and delay the recovery of motor response for several days. The development of additional tools, including electrophysiological examinations (electroencephalography and somatosensory evoked potentials), neuroimaging and chemical biomarkers, may help to evaluate the extent of brain injury in these patients. Given the extensive literature existing on this topic and the confounding effects of TH on the strength of these tools in outcome prognostication after cardiac arrest, the aim of this narrative review is to provide a practical approach to post-anoxic brain injury when TH is used. We also discuss when and how these tools could be combined with the neurological examination in a multimodal approach to improve outcome prediction in this population.
\end{abstract}

\section{Review}

\section{Clinical scenario}

A 52-year old woman collapsed on the street and underwent bystander cardiopulmonary resuscitation. Emergency medical personnel arrived 8 minutes later and found the patient in asystole; cardiopulmonary resuscitation was continued and return of spontaneous circulation was finally obtained 23 minutes after arrest, after a total of $4 \mathrm{mg}$ intravenous epinephrine. The initial electrocardiogram suggested an inferior ST-elevation myocardial infarction. The patient was transferred to the emergency department and underwent emergency coronary angiography, which revealed a proximal right coronary artery occlusion, eventually treated by percutaneous stenting. At 90 minutes post arrest, the patient arrived in the ICU, hemodynamically stable but comatose, with bilateral flexor responses to painful stimuli and absent pupillary reflexes; she was not receiving sedative agents. Therapeutic hypothermia $(\mathrm{TH})$ was immediately initiated. When the patient's relatives arrived, they immediately asked about the extent of

\footnotetext{
* Correspondence: ftaccone@ulb.ac.be

${ }^{1}$ Department of Intensive Care, Hôpital Erasme, Université Libre de Bruxelles, Route de Lennik 808, 1070, Brussels, Belgium

Full list of author information is available at the end of the article
}

brain damage and chances for survival and neurological recovery.

\section{Hypoxic-ischemic encephalopathy: the problem}

Cardiac arrest (CA) is a devastating event associated with mortality rates in excess of 90\% [1]. Among patients who achieve return of spontaneous circulation, more than $40 \%$ survive to ICU admission and nearly $30 \%$ are discharged alive from the hospital. The most important reason for poor outcome remains the postcardiac arrest syndrome, a pathophysiological process characterized by three main components: brain injury, myocardial dysfunction, and systemic ischemia/reperfusion response [2]. The severity of these disorders is not uniform and may depend on the cause, the duration of the CA and the extension of the ischemic injury; however, brain injury remains the most common cause of death in these patients $[3,4]$.

\section{How to predict neurological outcomes in hypoxic-ischemic} encephalopathy

Prognostication in hypoxic-ischemic encephalopathy (HIE) is a particular challenge because decisions to withdraw 
life-sustaining therapies largely depend on predicted prognosis [4]. A systematic review highlighted how the neurological examination (absent pupillary light response or corneal reflexes, absent or posturing motor responses to pain, myoclonus status epilepticus), high serum neuron-specific enolase (NSE) and bilateral absence of cortical somatosensory evoked potentials (SSEPs) could reliably predict poor outcome in comatose survivors after CA [5]. Nevertheless, such an approach has been questioned recently; specifically, introduction of $\mathrm{TH}$ as a neuroprotective intervention after return of spontaneous circulation [6] may significantly influence the neurological examination and also potentially modify the prognostic value of circulating biomarkers of brain damage or the accuracy of SSEPs [7-9].

The aim of this review is to provide a practical approach to the comatose patient surviving after anoxic injury and treated with $\mathrm{TH}$, and to outline when and how the available tools should be combined with the neurological examination in a multimodal approach to improve the quality of prognostic assessment (Figure 1).

\section{Clinical examination}

Clinical manifestations after CA depend on the susceptibility of different brain regions to anoxia (for example, the cerebral cortex, thalamus and cerebellum are more susceptible than subcortical areas and the brainstem). After reperfusion, brainstem functions, including spontaneous breathing and reflexes, return more rapidly than those related to deep brain structures (for example, response to pain).

In patients not treated with $\mathrm{TH}$, a lack of motor response or extensor response to pain (Glasgow Coma Score - Motor Response (GCS-M) $\leq 2$ ), bilateral lack of pupillary reflexes and bilateral lack of corneal reflexes at 72 hours after CA have all been regarded as reliable signs of a poor prognosis [10]. Today, however, the clinical course of neurological recovery is obscured by sedation and muscle paralysis associated with $\mathrm{TH}$ during the first 24 to 48 hours post arrest, a period during which most survivors without significant brain injury might recover responsiveness. In addition, hypothermia may prolong the metabolism of sedative agents and induce drug accumulation, with significant impact on the timing of neurological recovery [11]. As such, early assessment of a poor prognosis based only on the clinical examination may contribute to withdrawal of lifesustaining therapy in nearly $20 \%$ of patients who may otherwise have shown complete neurological recovery [12]. Use of sedatives could negatively influence the predictive value of clinical examination within the first 72 hours after TH initiation [13,14]. The amount of sedation used probably varies considerably between centers, and this may explain why the clinical examination has been reported as reliable in some studies and less reliable in others.

During the initial period after CA, when cooling and concomitant sedation is used, the only reliable prognostic information is limited to a minority of patients who

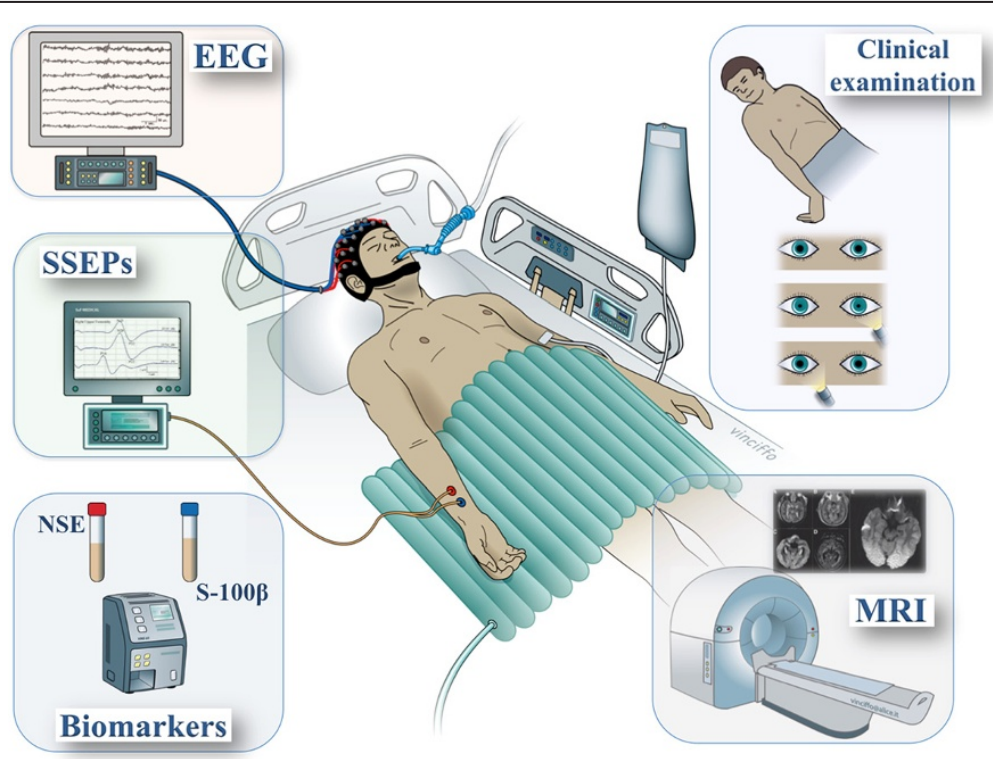

Figure 1 Multimodal approach to assess prognosis in comatose survivors after cardiac arrest treated with hypothermia. The multimodal approach to assess prognosis in comatose survivors after cardiac arrest treated with hypothermia should ideally include neurological examination combined with the use of electroencephalography (EEG) and somatosensory evoked potentials (SSEPs), the measurement of biomarkers (neuronspecific enolase (NSE) and S-100ß protein) and magnetic resonance imaging (MRI). 
develop dilated, unreactive pupils and loss of all brainstem functions as signs of total brain infarction and/or herniation [4]. The detection of asymmetrical motor response or stretch reflexes should indicate the need for a neuro-radiological investigation to detect focal brain injury; however, use of neuromuscular blockers with $\mathrm{TH}$ may limit these clinical signs to being present only on admission. Great care should be taken to avoid a premature diagnosis of brain death because recovery of brainstem function may occur even in more severe cases [15]. In clinical practice, additional tools - including electroencephalography (EEG) and neuroimaging - should be used to confirm extensive brain injury and swelling.

When sedation is weaned during rewarming, recovery of at least a localizing motor response to pain (GCS-M 25 ) is a sign of a favorable prognosis [16] and no further diagnostic tests are necessary if the patient continues to improve over subsequent days. On the other hand, if the patient remains unresponsive to pain or with only a stereotypic motor response $(\mathrm{GCS}-\mathrm{M}<4)$, the prognosis worsens each day without sedation and complementary prognostic tests have to be considered. Indeed, GCS-M $\leq 2$ alone on day 3 was associated with a false positive rate (FPR; that is, the proportion of patients misclassified when this variable is used) for poor outcome of 12 to $24 \%[17,18]$, whereas the combination of such abnormalities with myoclonus or absent brainstem reflexes (that is, pupillary and corneal reflexes) reduced the FPR to $<4 \%$ [17]. Pupillary and corneal reflexes should be tested daily in all patients, because their absence has been associated with poor prognosis in several studies [18-20]. However, few data are available about changes in these reflexes over time and the reactivity of constricted pupils or reaction to corneal stimulation may be difficult to assess reliably and can also be altered by deep sedation. Finally, the optimal timing to define prognosis using the neurological examination remains unknown. One could propose the need to delay prognosis assessment until 72 hours after normothermia has been achieved (that is, 4 to 5 days after CA), but no reliable data are available on the reliability and predictive value of clinical tests at this timepoint [14].

Clinical seizures are reported in about one-quarter of CA victims [21,22], but various forms of motor manifestations are often misinterpreted as seizures [23]. Myoclonus is a common event following CA that may or may not be an epileptic manifestation [24]. Occasional myoclonic jerks have little prognostic value in patients suffering from HIE. In a recent study, post-hypoxic myoclonus was reported in $20 \%$ of patients, $9 \%$ of whom had a good outcome [24]. Generalized (including face and limbs) myoclonus is often associated with burst suppression on EEG and is an ominous sign, especially if it occurs within the first 24 hours and persists for more than 30 minutes (that is, status myoclonus) [25]. Before the introduction of $\mathrm{TH}$, status myoclonus was considered a reliable sign of poor prognosis if it occurred following a primary CA [5], whereas good outcome was occasionally reported if the arrest was of hypoxic origin [26]. Since myoclonus usually occurs early and is usually suppressed by sedatives, status myoclonus is less frequently observed in hypothermia-treated CA survivors and cannot constitute by itself a sign of poor outcome [27].

\section{Electroencephalography}

The use of EEG is advocated to detect seizures and postanoxic status epilepticus, which occur in 10 to $40 \%$ of patients and are associated with a poorer outcome $[19,21,22]$, particularly when detected early during TH [28]. Nevertheless, good neurological outcome has been reported following aggressive anti-epileptic therapy for seizures occurring in the rewarming phase [29], especially in selected patients (that is, those with preserved brainstem reflexes, present cortical response on SSEPs and a reactive EEG).

In addition to seizure detection, EEG has been used to identify specific patterns associated with outcome during HIE (Figure 2). A dichotomized definition of EEG patterns, such as malignant or benign, has been developed. EEGs are considered to have a malignant pattern if postanoxic status epilepticus, alpha coma or burst suppression or generalized suppression is present. Other EEG patterns, including a generalized slowing activity, generalized alpha-theta frequencies or the presence of epileptiform discharges, are considered benign or of unclear significance. In CA patients not treated with $\mathrm{TH}, 84 \%$ of survivors had benign patterns whereas $88 \%$ of nonsurvivors had malignant patterns [30]. In a recent study, $12 \%$ of survivors and $86 \%$ of nonsurvivors after CA had a malignant EEG pattern within the first 3 days [19]; interestingly, a malignant EEG pattern was associated with a 0\% FPR to discriminate patients with good and poor outcome in those treated with TH in this study. However, benign EEG patterns could not distinguish patients with neurological recovery in another study [31]. These data suggest that a malignant pattern could be used to predict extensive brain injury after CA, regardless of the use of $\mathrm{TH}$; however, other benign findings or findings of unclear significance are not predictive of neurological recovery.

Dynamic changes in the EEG (that is, cerebral reactivity) are dependent on the integrity of the ascending reticular activating system and are strongly associated with arousal [32]. A nonreactive EEG, defined as the absence of any reproducible change in amplitude or frequency upon patient stimulation, was significantly associated with in-hospital mortality after CA [17,19]. EEG 


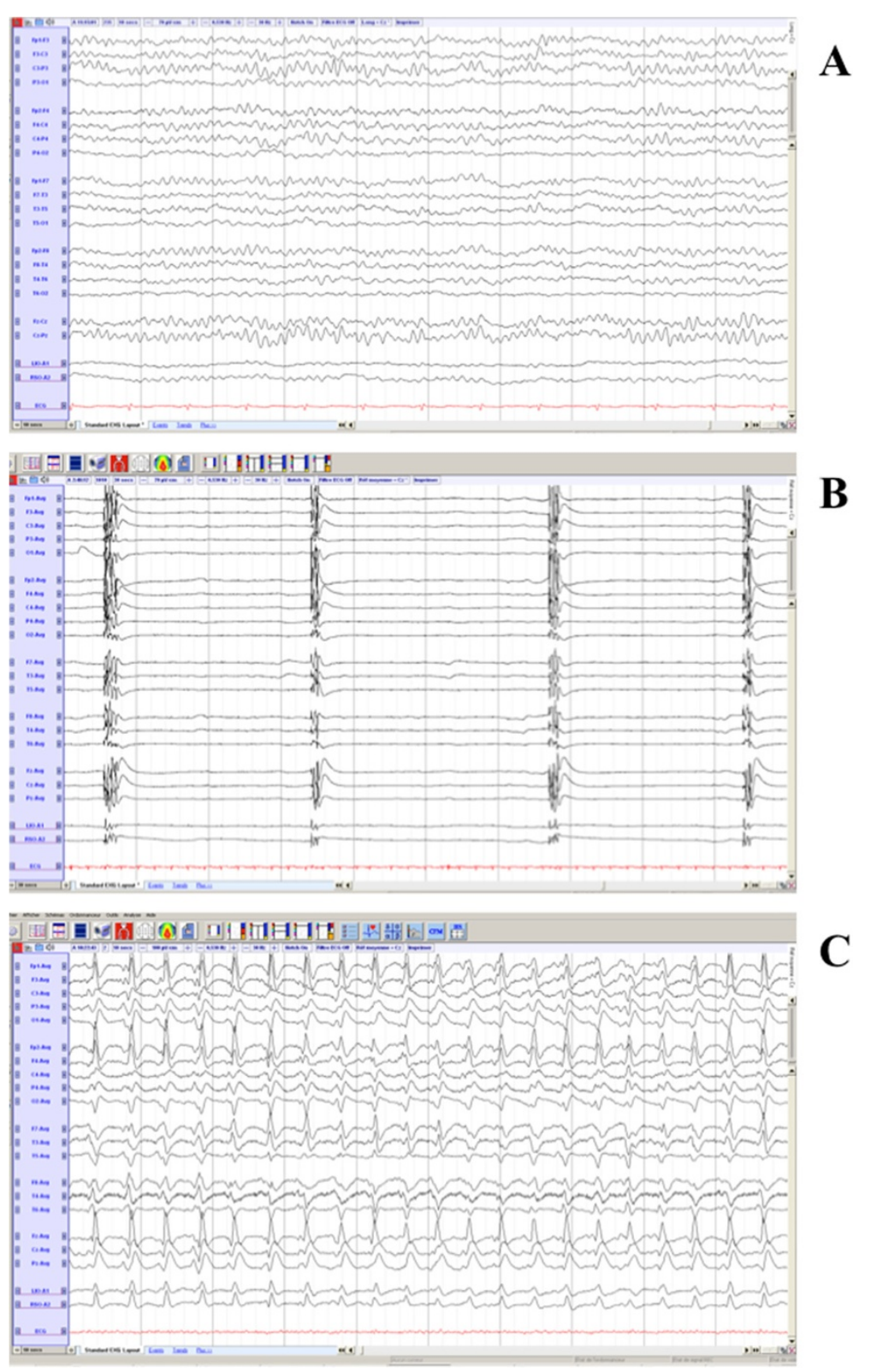

Figure 2 Electroencephalogram findings from resuscitated patients after cardiac arrest. (A) Electroencephalogram (EEG) recorded during therapeutic hypothermia, showing an example of continuous EEG: the patient had complete recovery of consciousness. (B) Burst-suppression findings during normothermia; the patient had concomitant myoclonus and bilateral absent N20 cortical responses to somatosensory evoked potentials, and eventually died. (C) Generalized periodic epileptiform discharges at 36 hours after hospital admission; we decided to withdraw care on day 5 because of persistent coma with posturing and absent pupillary reflexes.

reactivity also had a better predictive value for neurological outcome than malignant/benign EEG patterns and predicted awakening in patients with an EEG pattern of alpha-coma after CA [33,34]. Nevertheless, standard EEG in these studies was performed only at the end of treatment, under normothermic conditions. In patients treated with $\mathrm{TH}$ monitored with continuous EEG, a nonreactive EEG was strongly associated with a poor outcome $[17,19]$, with an even better predictive value than SSEPs [28]. On the other hand, a reactive EEG is often associated with a good recovery [28]. Moreover, the presence of a continuous EEG pattern (as opposed to an EEG showing flat periods and/or spontaneous burst-suppression patterns) early during $\mathrm{TH}$ was associated with a high probability of recovery [35,36]. Thus, when an EEG is performed in comatose survivors after CA, both the EEG pattern and reactivity should be recorded to assess the extent of brain injury. 
Importantly, EEGs have several limitations in this setting. First, lack of a universally accepted classification for different EEG patterns can lead to differences in definitions. As such, post-anoxic paroxysms - classified as periodic electrographic discharges by some neurologists - could be considered as post-anoxic status epilepticus by others. Recently, a simplified classification with four major EEG patterns after CA was proposed: flat pattern, continuous pattern, suppression-burst pattern, and electrographic status epilepticus $[35,37]$. This approach provided valuable prognostic information, could be easily interpreted even by non-neurologists and may facilitate data comparison among studies; however, these findings need to be validated in a larger patient cohort.

Second, the diagnosis of absent/present EEG reactivity relies on the experience and expertise of the neurologist who interprets the EEG. The exact stimulus needed to reproduce EEG changes and reactivity has not been clearly standardized. Moreover, muscle activity after weaning from sedation may produce artifacts and necessitate muscle relaxation. Reactivity can thus be easily tested only during $\mathrm{TH}$, but few data are available on the time course of EEG reactivity after CA.

Finally, continuous EEG may enable a better evaluation of brain function over time; however, a recent statement recommended continuous EEG over intermittent EEG only for seizure detection in patients with refractory status epilepticus, whereas both techniques are effective at improving prognostication in post-anoxic coma [38].

\section{Somatosensory evoked potentials}

The SSEP is a small $(<10$ to $50 \mu \mathrm{V})$ electrical signal that can be recorded non-invasively from the skull after administering a set of electrical stimuli to one of the peripheral nerves. In CA patients, the median nerve is most commonly stimulated bilaterally at the wrist. Electrodes are then placed at the elbow, Erb's point, the cervical medulla (peripheral) and on the parietal and frontal cortex (cortical); specific responses are commonly identified as N9 for Erb's point, N14 for the cervical medulla and N20 for cortex [39]. The cortical responses can only be reliably interpreted when the peripheral and spinal responses are also present (Figure 3). If peripheral responses are not present, this may be due to peripheral nerve damage. For prognosis of a poor outcome after $\mathrm{CA}$, only the short cortical latencies (N20, expected to appear 20 milliseconds after median nerve stimulation) are used. In order to have absent SSEPs, predictive of a poor outcome, cortical responses have to be absent bilaterally in a technically well-performed test [40]. In patients who remain comatose after CA, SSEPs have been shown to reliably predict poor outcome $[5,14]$.
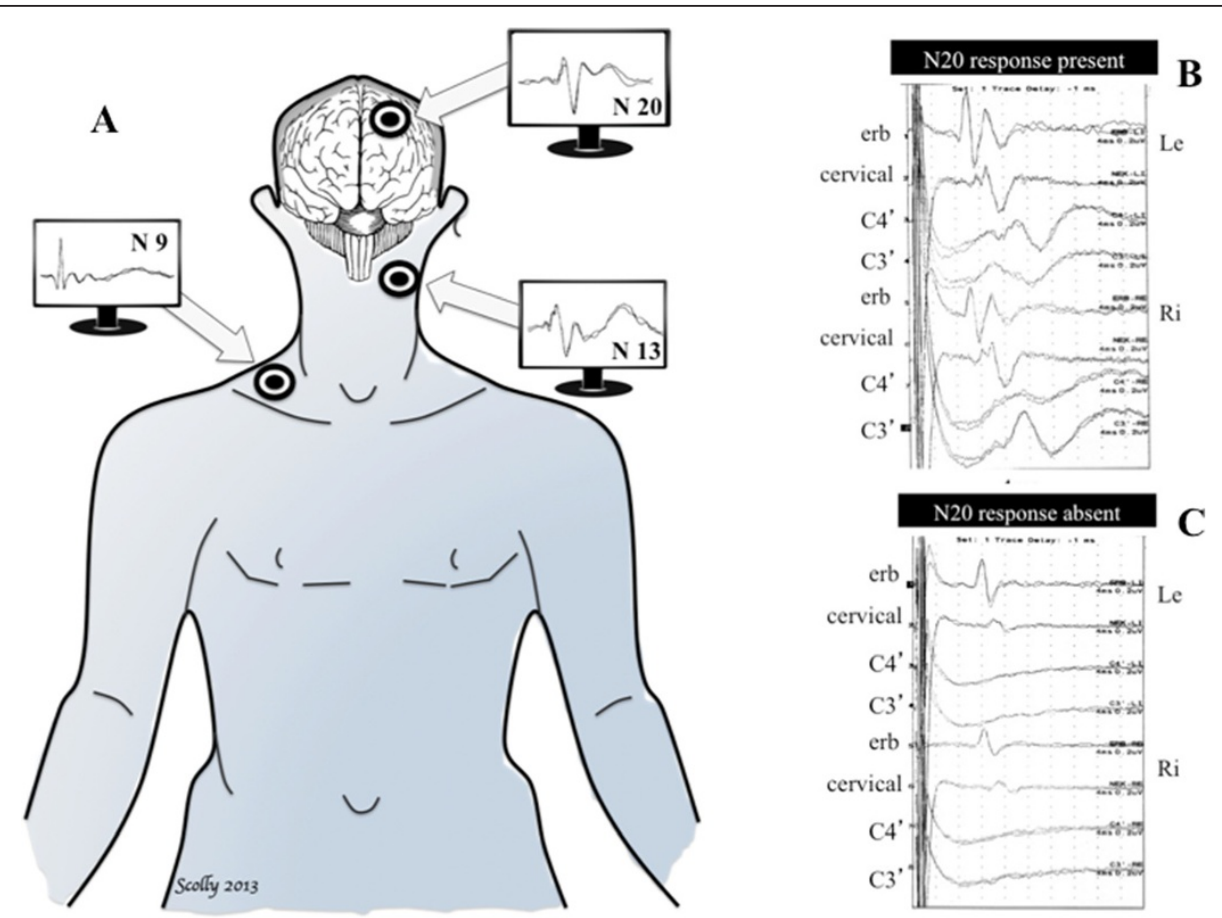

Figure 3 Somatosensory evoked potentials. (A) In comatose survivors after cardiac arrest, somatosensory evoked potentials are elicited by transcutaneous electrical stimulation applied to the median nerve and then recorded at Erb's point (N9), the cervical medulla (N13) and the controlateral cortex (N20). (B) Example of present N20 cortical response (C3') in two comatose patients after cardiac arrest. (C) Example of absent N20 cortical response (C3') in two comatose patients after cardiac arrest. 
Cortical N20 responses are not influenced by moderate sedation or metabolic disturbances and remain present even at a sedation level that is sufficient to induce an isoelectric EEG [39]. Propofol produces minimal to $<10 \%$ suppression of the SSEP amplitude [41]. Midazolam and opioids also have only a moderate effect on SSEP amplitude and latency. Remifentanil can suppress the cortical SSEP components by 20 to $80 \%$ when given at high doses $(0.8 \mu \mathrm{g} / \mathrm{kg} /$ minute $)$, as used during neuromonitoring in the operating room [42].

A systematic review of studies on CA patients before $\mathrm{TH}$ implementation showed that bilateral absence of N20 on day 1 or day 3 after CA could certainly predict poor neurological outcome. Some false positives were identified when SSEPs were performed too early (within 1 day) after the anoxic injury; thus, this test should not be performed earlier than 24 hours after arrest [43]. In two large prospective studies performed in patients treated with $\mathrm{TH}$, the bilateral absence of N20 at rewarming (that is, on day 2 or day 3) was a reliable tool to predict poor outcome, with a FPR of $0 \%[17,18]$, and a pooled analysis of recent studies $[14,17,18,44,45]$ still gave a very low FPR of $<0.5 \%$. Unfortunately, only a small proportion of patients with a poor outcome after resuscitation have absent SSEPs, resulting in a low sensitivity [46]. Moreover, preservation of the N20 response does not imply a favorable outcome; indeed, almost one-half of the patients with a present N20 will have a poor outcome.

A limitation of SSEP is that it has only moderate interpretation reproducibility. In one study, SSEP recordings from 56 patients with HIE were interpreted independently by five experienced clinical neurophysiologists. The inter-observer agreement was moderate (kappa 0.52, $95 \%$ confidence interval $=0.20$ to 0.65 ) with the main source of disagreement related to noise levels [47], which should therefore be reduced as much as possible - for example, by giving muscle relaxants to patients with too much muscular activity. Electrical ICU equipment that can interfere with readings should also be turned off whenever possible. Providing more stimuli (up to 1,000 or more) and increasing the stimulus intensity can also improve the signal-to-noise ratio [47].

\section{Biomarkers}

Biomarkers are quantifiable biological substances, usually peptides, which can be easily measured in peripheral blood. Biomarkers of brain injury in comatose survivors from CA include NSE and S-100 $\beta[48,49]$.

Before widespread use of TH, serum NSE levels $>33 \mu \mathrm{g} / \mathrm{l}$ at 72 hours after CA were strongly associated with poor prognosis [40,50]; the reported FPR varied from 0 to 3\% [5]. However, Tiainen and colleagues showed that hypothermia may significantly reduce serum NSE levels, probably by selective attenuation of neuronal injury [8]. The cutoff values for NSE predictive of a poor outcome were also significantly higher in patients treated with $\mathrm{TH}$ than in those without cooling [51]. Finally, a single high NSE measurement on day 3 after $\mathrm{CA}$ and $\mathrm{TH}$ remained associated with a poor outcome but with a FPR ranging from 7 to $29 \%[18,19]$, and much higher NSE cutoff values $(>50$ to $80 \mu \mathrm{g} / \mathrm{l}$ ) would be necessary to predict poor outcome without false positives [52,53].

High concentrations of S-100 $\beta$ have also been found in patients remaining comatose after CA; however, different cutoff levels, ranging from 0.2 to $1.5 \mathrm{mg} / \mathrm{l}$, have been proposed to predict poor neurological outcome in this setting $[54,55]$. Before widespread use of TH, S$100 \beta$ levels within the first 2 days after hospital admission could predict outcome in comatose patients with HIE with a FPR of 2 to 5\% [5]. More recent studies have compared the predictive values of NSE and S-100 $\beta$ after $\mathrm{TH}$, yielding conflicting results $[8,40]$. Although S-100 $\beta$ has a very short half-life and could potentially be more sensitive for detecting extensive brain damage within the first 24 hours of hypoxic injury, most of the existing data relate to NSE, which remains the most commonly used biomarker in this setting. Furthermore, NSE levels have been shown to have a strong correlation to several other prognostic indicators after CA, including EEG changes $[56,57]$.

Importantly, both biomarkers have important pitfalls; because NSE is found in red blood cells and platelets levels may increase in cases of hemolysis or NSEproducing masses, whereas $\mathrm{S}-100 \beta$ can be released from adipocytes and chondrocytes, and levels may thus increase as a result of chest compressions [58]. Variability in handling of blood samples, including storage, centrifugation and freezing procedures, are other potential causes of error [59]. Disadvantages also include the lack of standardized assays, which may explain the differences in reported cutoff levels reported in the literature [60]. Finally, if CA occurs concomitantly with other brain diseases, such as stroke or traumatic brain injury, the contribution of HIE to elevated biomarker levels may be difficult to distinguish.

\section{Imaging}

Current guidelines state that available data are insufficient to support the use of computed tomography $(\mathrm{CT})$ imaging in neuro-prognostication of comatose CA survivors [61]. Nevertheless, early CT could be helpful to rule out a cerebral cause of coma and/or CA, especially in cases with preceding neurological symptoms, in cases with nonshockable rhythms or in young patients without cardiovascular risk factors [62,63]. Moreover, as brain death may occur in up to $10 \%$ of patients in the days 
following CA, CT can provide evidence of an irreversible neurological catastrophe in patients being considered for brain death determination.

Some studies have evaluated the predictive value of CT for predicting neurological outcome after CA. A loss of distinction between gray and white matter, indicating cerebral edema, has been associated with a lower likelihood of good outcome [64-66]. Other studies have suggested that a ratio of Hounsfield units in the gray matter versus the white matter $<1.18$ can accurately predict poor outcome $[67,68]$. However, these studies are limited by the small numbers of patients. The largest study to date, including 151 patients, illustrated the utility of CT imaging by incorporating whole brain Hounsfield units; a decrease in this value, especially in combination with traditional clinical features, was highly specific for predicting poor outcome while maintaining acceptable sensitivity [69].

Magnetic resonance imaging (MRI) provides a more sensitive indication of brain injury after CA compared with $\mathrm{CT}$, and the use of apparent diffusion coefficient values has recently helped to quantify the degree of injury (Figure 4) [70-72]. Apparent diffusion coefficient maps are used to create diffusion-weighted images (DWI), a technique that relies on the concept of restricted diffusivity of water across dysfunctional cell membranes, such as those of ischemic neurons. Cytotoxic edema occurs secondary to failure of ion pumps, leading to increased intracellular water content as ions are no longer adequately pumped out of ischemic neurons. Fluid-attenuated inversion recovery (FLAIR) sequences are T2-weighted, but with suppression of the cerebrospinal fluid signal, allowing for high sensitivity but relatively weak specificity for lesions. FLAIR is particularly sensitive to vasogenic edema.

Regional (that is, the occipital and temporal lobes), spatial (that is, widespread and diffuse lesions) or temporal (that is, absence of resolution in FLAIR abnormalities) MRI findings may provide better insight into the degree and mechanisms of hypoxic-ischemic brain injury, and hence better predict outcome in comatose survivors, including those treated with $\mathrm{TH}$ [73-75]. Bilateral hippocampal hyperintense signals on DWI and FLAIR also appear to be specific imaging indicators of poor prognosis in patients who suffer global hypoxic-ischemic injury [76]. The ideal timing to perform MRI would be 2 to 5 days after CA (or after TH, if performed); during this time, DWI abnormalities in combination with the neurological examination on day 3 improved the sensitivity for predicting poor outcome by $38 \%$, while maintaining $100 \%$ specificity [70]. However, one should emphasize that most studies of neuroimaging for CA patients are limited by their retrospective nature, heterogeneous populations (for example, not all patients were comatose), and the self-fulfilling prophecy of early withdrawal of life-sustaining therapy (that is, the falsely pessimistic interpretation of prognostic variables concurrently used to forgo life support) [77]. Additionally,

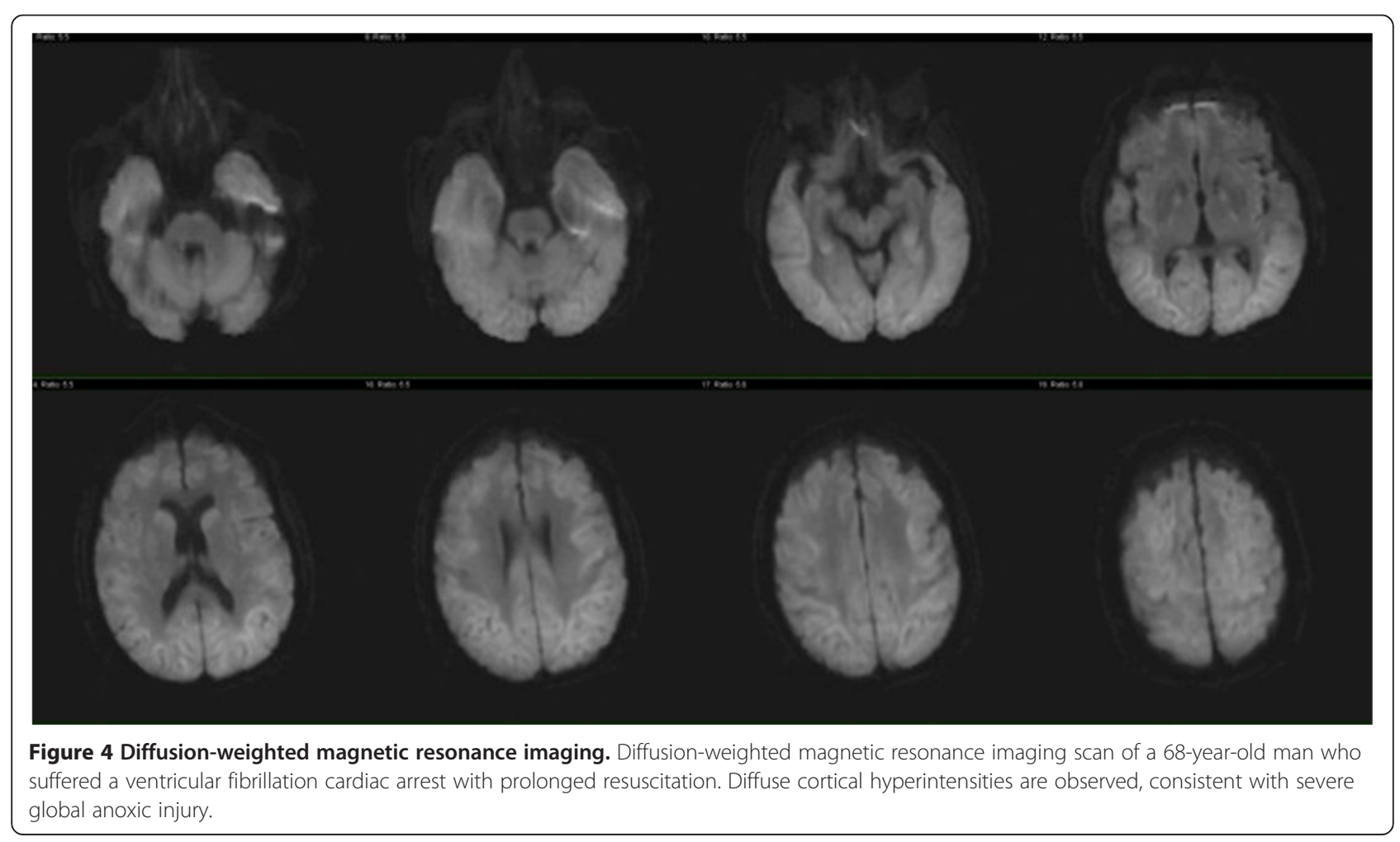


the prediction of good outcome remains even more uncertain than that of poor outcome, and both CT and MRI need to be further evaluated in well-conducted prospective studies in the CA population.

\section{Multimodal prognostic algorithm}

Previous studies have suggested some benefits of a multimodal approach. Before the implementation of $\mathrm{TH}$, the addition of NSE measurements to the Glasgow Coma Scale and SSEP increased the predictability of poor neurological outcome from $64 \%$ to $76 \%$ [78]. Combination of the neurological examination, EEG findings, SSEPs and two serum biomarkers improved prognostic value with no false positives for death [79]. In patients treated with TH, the use of SSEPs, NSE and EEG increased the number of patients identified as having a poor outcome from $75 \%$ to $88 \%$ [52]. Also, the combination of arrest duration, Glasgow Coma Score and noncontrast brain CT findings on admission was a strong predictor of mortality with severe neurological disability, showing a $100 \%$ specificity and positive predictive value [67]; however, the quite small cohort population and the absence of clear recommendation for withdrawal of care are major confounders for this study.

Importantly, the precise multimodal approach will vary among centers depending on the availability of electrophysiological monitoring, technical expertise and laboratory facilities, and the use of several prognostic tools does increase costs. Also, self-fulfilling prophecy should be avoided and considerable efforts have to be addressed to combine the different variables to accurately predict neurological outcome. Finally, decisions to withdraw life support should also require good education and training, should require good communication between the ICU team, and should be based on the ethical principles of autonomy, beneficence, nonmaleficence and justice.

Taking into account all of the previous referenced studies, we thus propose a combination of several prognostic tools to improve the accuracy of predicting good and poor outcomes after HIE and TH (Figure 5). After initial neurological examination (at hospital admission and before sedation and muscular paralysis to induce $\mathrm{TH}$, whenever possible), continuous or repeated standard EEG monitoring should be started already during $\mathrm{TH}$ to identify the presence of early seizures, of malignant EEG patterns and of EEG reactivity. Evidence of reactive EEG or continuous background activity indicates a high probability of good neurological recovery, and these patients usually wake up rapidly after rewarming and discontinuation of sedation. In contrast, malignant patterns - including burst suppression, generalized periodic epileptiform discharges and cerebral inactivity (that is, a flat EEG or unreactive background) - are associated

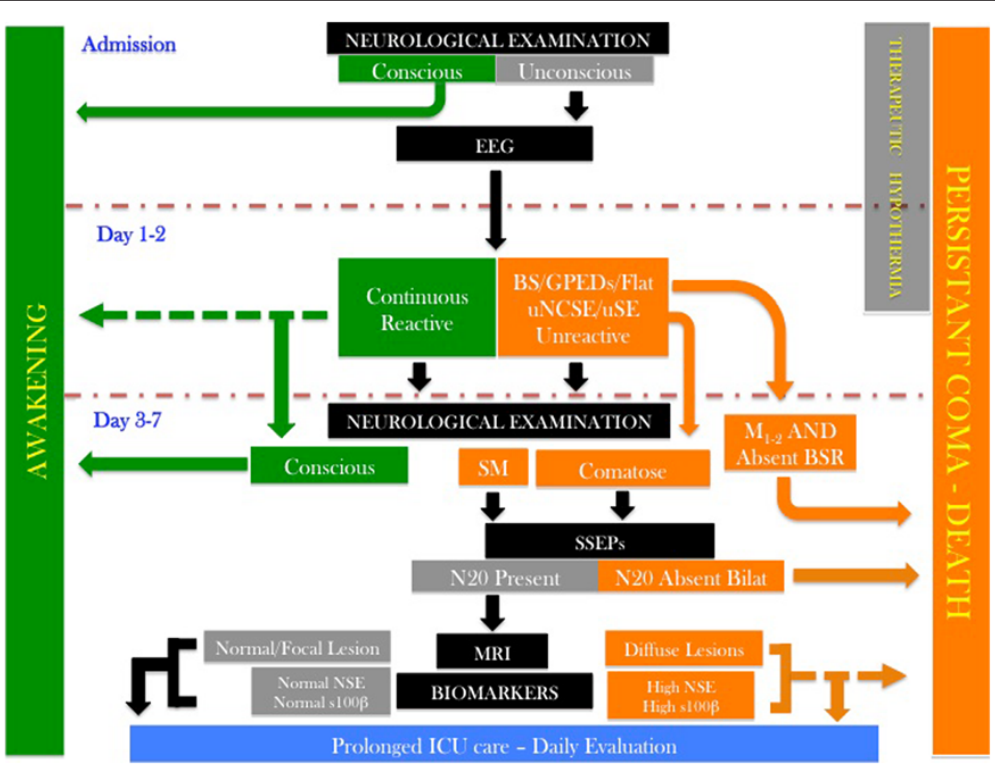

Figure $\mathbf{5}$ Multimodal prognostication of coma after cardiac arrest and therapeutic hypothermia. Summary of the suggested timing after cardiac arrest of all available tools that are used to predict poor outcome or neurological recovery from coma. This algorithm suggests that poor prognosis or neurological recovery should be considered when specific findings are present but this does not necessarily mean that withdrawal of care should be initiated, because this approach has not been validated. Dashed lines, lack of strong evidence to support the suggestion. High biomarker levels did not relate to a specific cutoff value because of several limitations affecting their measurements and accuracy (see text). BS, burst suppression; BSR, brainstem reflexes; EEG, electroencephalogram; GPED, generalized periodic epileptiform discharge; $M_{1-2}$, absent motor response or posturing; MRI, magnetic resonance imaging; N2O, cortical responses to somatosensory evoked potentials; NSE, neuron-specific enolase; SM, status myoclonus; SSEP, somatosensory evoked potential; UNCSE, unreactive nonconvulsive seizures; uSE, unreactive status epilepticuS. 
with poor outcome. Immediate initiation and prolonged therapy should be considered for post-anoxic status epilepticus, especially if it occurs in the rewarming phase in the absence of other signs of extensive brain injury; in contrast, early nonconvulsive seizures are often associated with a poor outcome, especially if associated with an unreactive EEG and nonresponse to anti-epileptic treatment. The effect of treatment on this kind of seizures is uncertain.

Importantly, no EEG finding should be used alone to predict poor outcome, and these negative EEG patterns need to be correlated with neurological examination at 48 to 72 hours after the end of $\mathrm{TH}$, when sedation has been withheld for at least 24 hours. If patients have generalized persistent status myoclonus during the first 24 hours, poor outcome can be predicted if it is associated with bilateral absence of N20 after rewarming. If SSEPs are not available, a malignant EEG pattern increases the likelihood of poor prognosis but further diagnostic work-up (including brain imaging and biomarkers) should be considered. It is reasonable to assume a poor neurological outcome in patients with absent pupillary/ corneal reflexes and GCS-M $\leq 2$ on day 3 after CA. However, prognostic accuracy is increased if these signs are associated with an unreactive EEG or malignant patterns. In other comatose patients, bilateral absence of N20 potentials 48 to 72 hours after CA indicates irreversible brain damage. If these findings (that is, malignant EEG, poor clinical findings and bilateral absence of N20 potentials) are absent, prognostication becomes more difficult. The combination of high NSE and S-100 $\beta$ levels with widespread DWI or FLAIR MRI lesions should be considered as additional tools to identify extensive cerebral injury. Because these methods have some limitations, they should not be used to make final decisions on treatment levels. Rather, a prolonged observation period ( 1 to 2 weeks) should be considered to allow for delayed neurological recovery.

\section{Perspectives and areas for future clinical investigation}

Considering the limits of the neurological examination, certain electrophysiological tests have been proposed. A simplified EEG method with a limited number of EEG electrodes, in combination with amplitude-integrated EEG, could be used in comatose survivors of CA, and may provide relevant and rapid bedside information that could be evaluated also by non-neurologists [35,37]. Functional deficiency of the auditory-frontal cortex network of auditory discrimination is a common finding shared by different neurological disorders with cognitive impairment [80]. This deficiency can be measured with the so-called mismatch negativity, an EEG finding that is elicited during a specific auditory stimulus using sounds that differ in pitch, duration or loudness. Mismatch negativity has been shown to better predict awakening than SSEPs in patients remaining comatose several days after CA [81]. In a study by Tzovara and colleagues, all nonsurvivors showed deterioration in mismatch negativity between two measurements, whereas all those patients who had an early improvement in auditory discrimination regained consciousness [82]. Finally, long latency evoked potentials, such as P70 and P300, have been correlated with neurological status in CA survivors after 3 and 6 months; however, these potentials are difficult to perform in the early phase and do not provide additional predictive value to the available electrophysiological tests $[9,83]$.

Analysis of the time course of biomarkers could also improve their predictive value. An increase in NSE levels by $>2 \mu \mathrm{g} / \mathrm{l}$ between 24 and 48 hours after CA was reported as a strong predictor of poor outcome [48]. Preliminary studies have shown that other blood biomarkers, including glial fibrillary acidic protein, neurofilaments or tau protein, may represent alternative biomarkers [84-86]. Also, because the post-CA syndrome activates a systemic inflammatory response syndrome similar to that of sepsis [2], C-reactive protein, copeptin and especially procalcitonin could be considered adjunctive tools to assess prognosis [87-89]. The combination of such molecules with biomarkers of heart injury, such as cardiac troponins and brain natriuretic peptide, along with novel biomarkers, including circulating cell-free DNA and micro-RNAs, could create a multipanel of biomarkers to incorporate into the prognostication process of CA patients [58].

Advanced MRI techniques could provide interesting information, although their usefulness is less clear than conventional neuroimaging techniques. Some of the newer techniques include diffusion tensor imaging, fractional anisotropy, functional MRI (including restingstate and task-specific functional MRI) using blood oxygen level-dependent contrast, and high angular resolution diffusion imaging tractography. These imaging techniques can evaluate brain oxygenation, regional activation in response to external stimuli, neuronal structure and axonal myelination, and all these findings may give new insight into the investigation of postanoxic brain injury.

\section{Conclusions}

Accurate prognostication of comatose patients suffering from HIE and treated with TH can be obtained only 72 to 96 hours after $\mathrm{CA}$ and requires a multimodal approach. The neurological examination remains the gold standard; however, motor responses may be delayed up to 5 days in patients undergoing $\mathrm{TH}$ and neurological examination is not sufficient to accurately predict prognosis. The addition of EEG could improve prognostic 
accuracy, in particular the presence of an early (within 24 hours from CA) reactive EEG pattern as a finding suggestive of good prognosis, whereas a nonreactive or burst-suppressed EEG pattern is associated with a poor outcome. Bilateral absence of N20 at 48 to 72 hours is almost invariably associated with a poor prognosis. Serum biomarkers of brain damage (NSE and S-100 $\beta$ ) may be useful to assess the severity of acute brain injury; however, they should never be used alone and further studies are needed to better define predictive cutoff levels. Findings from MRI investigations could potentially help to identify patients with extensive hypoxicischemic brain injury. Additional tools are under investigation to further improve the quality of prognosis assessment in this population.

\section{Key messages}

- The clinical examination remains the gold standard for assessing prognosis in comatose survivors after $\mathrm{CA}$; however, the use of sedatives and cooling procedures severely limit the early use of clinical findings in this setting.

- Previous guidelines should no longer be applied in clinical practice to assess brain function in patients treated with $\mathrm{TH}$.

- There is no optimal timing to assess prognosis after CA.

- We recommend the use of a multimodal approach, including full neurological examination with at least SSEPs and EEG, to help with coma prognostication after $\mathrm{CA}$ and $\mathrm{TH}$.

\footnotetext{
Abbreviations

CA: Cardiac arrest; CT: Computed tomography; DWI: Diffusion-weighted images; EEG: Electroencephalography; FLAIR: Fluid attenuated inversion recovery; FPR: False positive rate; GCS-M: Glasgow Coma Score - Motor Response; HIE: Hypoxic-ischemic encephalopathy; MRI: Magnetic resonance imaging; NSE: Neuron-specific enolase; SSEP: Somatosensory evoked potential; $\mathrm{TH}$ : Therapeutic hypothermia.
}

\section{Competing interests}

HF received lecture fees from Natus ${ }^{\oplus}$ Inc. The remaining authors declare that they have no competing interests.

\section{Authors' contributions}

FST planned and drafted the manuscript. All the authors contributed to literature research, data interpretation and critical revision of the manuscript. All authors read and approved the final manuscript.

\section{Acknowledgements}

The authors would like to dedicate this article to Dr CA Wijman whose research contributed hugely to the assessment of prognosis of comatose patients after cardiac arrest. They would like to express gratitude to designer Vincenzo Ciffo (vinciffo@alice.it) for drawing Figure 1.

\section{Author details}

${ }^{1}$ Department of Intensive Care, Hôpital Erasme, Université Libre de Bruxelles, Route de Lennik 808, 1070, Brussels, Belgium. ${ }^{2}$ Department of Clinical Sciences, Section for Neurology, Skåne University Hospital, Lund University, 221 85, Lund, Sweden. ${ }^{3}$ Department of Intensive and Perioperative Care,
Skåne University Hospital, Lund University, 221 85, Lund, Sweden. ${ }^{4}$ Department of Neurology, Temple Medical Center, 6C, New Haven, CT 06510, USA. ${ }^{5}$ Department of Intensive Care, Academisch Medisch Centrum Meibergdreef 9, 1105 AZ, Amsterdam, The Netherlands. 'Department of Intensive Care Medicine, CHUV_Lausanne University Hospital, CH-1011, Lausanne, Switzerland. 'Department of Anesthesiology and Intensive Care, University of Siena, Viale Bracci 1, 53100, Siena, Italy.

Published: 14 January 2014

\section{References}

1. Stiell IG, Nichol G, Leroux BG, Rea TD, Ornato JP, Powell J, Christenson J, Callaway CW, Kudenchuk PJ, Aufderheide TP, Idris AH, Daya MR, Wang HE, Morrison LJ, Davis D, Andrusiek D, Stephens S, Cheskes S, Schmicker RH, Fowler R, Vaillancourt C, Hostler D, Zive D, Pirrallo RG, Vilke GM, Sopko G, Weisfeldt M: Early versus later rhythm analysis in patients with out-ofhospital cardiac arrest. N Engl J Med 2011, 365:787-797.

2. Stub D, Bernard S, Duffy SJ, Kaye DM: Post cardiac arrest syndrome: a review of therapeutic strategies. Circulation 2011, 123:1428-1435.

3. Oddo M, Rossetti AO: Predicting neurological outcome after cardiac arrest. Curr Opin Crit Care 2011, 17:254-259.

4. Dragancea I, Rundgren M, Englund $E$, Friberg $H$, Cronberg T: The influence of induced hypothermia and delayed prognostication on the mode of death after cardiac arrest. Resuscitation 2013, 84:337-342.

5. Wijdicks EF, Hijdra A, Young GB, Bassetti CL, Wiebe S: Practice parameter: prediction of outcome in comatose survivors after cardiopulmonary resuscitation (an evidence-based review): report of the Quality Standards Subcommittee of the American Academy of Neurology. Neurology 2006, 67:203-210.

6. Nolan JP, Morley PT, Vanden Hoek TL, Hickey RW, Kloeck WG, Billi J, Bottiger BW, Morley PT, Nolan JP, Okada K, Reyes C, Shuster M, Steen PA, Weil MH, Wenzel V, Hickey RW, Carli P, Vanden Hoek TL, Atkins D: Therapeutic hypothermia after cardiac arrest: an advisory statement by the advanced life support task force of the International Liaison Committee on Resuscitation. Circulation 2003, 108:118-121.

7. Fugate JE, Wijdicks EF, White RD, Rabinstein AA: Does therapeutic hypothermia affect time to awakening in cardiac arrest survivors? Neurology 2011, 77:1346-1350.

8. Tiainen $M$, Roine RO, Pettila $V$, Takkunen $O$ : Serum neuron-specific enolase and S-100B protein in cardiac arrest patients treated with hypothermia. Stroke 2003, 34:2881-2886.

9. Tiainen M, Poutiainen E, Kovala T, Takkunen O, Happola O, Roine RO: Cognitive and neurophysiological outcome of cardiac arrest survivors treated with therapeutic hypothermia. Stroke 2007, 38:2303-2308.

10. Levy DE, Bates D, Caronna JJ, Cartlidge NE, Knill-Jones RP, Lapinski RH, Singer BH, Shaw DA, Plum F: Prognosis in nontraumatic coma. Ann Intern Med 1981, 94:293-301.

11. Tortorici MA, Kochanek PM, Poloyac SM: Effects of hypothermia on drug disposition, metabolism, and response: a focus of hypothermia-mediated alterations on the cytochrome P450 enzyme system. Crit Care Med 2007, 35:2196-2204.

12. Perman SM, Kirkpatrick JN, Reitsma AM, Gaieski DF, Lau B, Smith TM, Leary M, Fuchs BD, Levine JM, Abella BS, Becker LB, Merchant RM: Timing of neuroprognostication in postcardiac arrest therapeutic hypothermia. Crit Care Med 2012, 40:719-724.

13. Samaniego EA, Mlynash M, Caulfield AF, Eyngorn I, Wijman CA: Sedation confounds outcome prediction in cardiac arrest survivors treated with hypothermia. Neurocrit Care 2011, 15:113-119.

14. Kamps MJ, Horn J, Oddo M, Fugate JE, Storm C, Cronberg T, Wijman CA, Wu O, Binnekade JM, Hoedemaekers CW: Prognostication of neurologic outcome in cardiac arrest patients after mild therapeutic hypothermia: a meta-analysis of the current literature. Intensive Care Med 2013, 39:1671-1682.

15. Webb AC, Samuels OB: Reversible brain death after cardiopulmonary arrest and induced hypothermia. Crit Care Med 2011, 39:1538-1542.

16. Schefold JC, Storm C, Kruger A, Ploner CJ, Hasper D: The Glasgow Coma Score is a predictor of good outcome in cardiac arrest patients treated with therapeutic hypothermia. Resuscitation 2009, 80:658-661.

17. Rossetti AO, Oddo M, Logroscino G, Kaplan PW: Prognostication after cardiac arrest and hypothermia: a prospective study. Ann Neurol 2010, 67:301-307 
18. Bouwes A, Binnekade JM, Kuiper MA, Bosch FH, Zandstra DF, Toornvliet AC, Biemond HS, Kors BM, Koelman JH, Verbeek MM, Weinstein HC, Hijdra A, Horn J: Prognosis of coma after therapeutic hypothermia: a prospective cohort study. Ann Neurol 2012, 71:206-212.

19. Fugate JE, Wijdicks EF, Mandrekar J, Claassen DO, Manno EM, White RD, Bell MR, Rabinstein AA: Predictors of neurologic outcome in hypothermia after cardiac arrest. Ann Neurol 2010, 68:907-914.

20. Rittenberger JC, Sangl J, Wheeler M, Guyette FX, Callaway CW: Association between clinical examination and outcome after cardiac arrest. Resuscitation 2010, 81:1128-1132.

21. Legriel S, Bruneel F, Sediri H, Hilly J, Abbosh N, Lagarrigue MH, Troche G, Guezennec P, Pico F, Bedos JP: Early EEG monitoring for detecting postanoxic status epilepticus during therapeutic hypothermia: a pilot study. Neurocrit Care 2009, 11:338-344.

22. Rittenberger JC, Popescu A, Brenner RP, Guyette FX, Callaway CW: Frequency and timing of nonconvulsive status epilepticus in comatose post-cardiac arrest subjects treated with hypothermia. Neurocrit Care 2012, 16:114-122.

23. Benbadis SR, Chen S, Melo M: What's shaking in the ICU? The differential diagnosis of seizures in the intensive care setting. Epilepsia 2010, 51:2338-2340.

24. Bouwes A, van Poppelen D, Koelman JH, Kuiper MA, Zandstra DF, Weinstein HC, Tromp SC, Zandbergen EG, Tijssen MA, Horn J: Acute posthypoxic myoclonus after cardiopulmonary resuscitation. BMC Neurol 2012, 12:63.

25. Wijdicks EF, Parisi JE, Sharbrough FW: Prognostic value of myoclonus status in comatose survivors of cardiac arrest. Ann Neurol 1994, 35:239-243.

26. Werhahn KJ, Brown P, Thompson PD, Marsden CD: The clinical features and prognosis of chronic posthypoxic myoclonus. Mov Disord 1997, $12: 216-220$

27. Lucas JM, Cocchi MN, Salciccioli J, Stanbridge JA, Geocadin RG, Herman ST, Donnino MW: Neurologic recovery after therapeutic hypothermia in patients with post-cardiac arrest myoclonus. Resuscitation 2012, 83:265-269.

28. Rossetti AO, Urbano LA, Delodder F, Kaplan PW, Oddo M: Prognostic value of continuous EEG monitoring during therapeutic hypothermia after cardiac arrest. Crit Care 2010, 14:R173.

29. Rossetti AO, Oddo M, Liaudet L, Kaplan PW: Predictors of awakening from postanoxic status epilepticus after therapeutic hypothermia. Neurology 2009, 72:744-749.

30. Young GB, Doig G, Ragazzoni A: Anoxic-ischemic encephalopathy: clinical and electrophysiological associations with outcome. Neurocrit Care 2005, 2:159-164.

31. Rothstein TL, Thomas EM, Sumi SM: Predicting outcome in hypoxicischemic coma. A prospective clinical and electrophysiologic study. Electroencephalogr Clin Neurophysiol 1991, 79:101-107.

32. Synek VM, Shaw NA: Epileptiform discharges in presence of continuous background activity in anoxic coma. Clin Electroencephalogr 1989, 20:141-146.

33. Thenayan EA, Savard M, Sharpe MD, Norton L, Young B: Electroencephalogram for prognosis after cardiac arrest. J Crit Care 2010, 25:300-304.

34. Kaplan PW, Genoud D, Ho TW, Jallon P: Etiology, neurologic correlations, and prognosis in alpha coma. Clin Neurophysiol 1999, 110:205-213.

35. Rundgren M, Westhall E, Cronberg T, Rosen I, Friberg H: Continuous amplitudeintegrated electroencephalogram predicts outcome in hypothermia-treated cardiac arrest patients. Crit Care Med 2010, 38:1838-1844.

36. Cloostermans MC, van Meulen FB, Eertman CJ, Hom HW, van Putten MJ: Continuous electroencephalography monitoring for early prediction of neurological outcome in postanoxic patients after cardiac arrest: a prospective cohort study. Crit Care Med 2012, 40:2867-2875.

37. Friberg H, Westhall E, Rosen I, Rundgren M, Nielsen N, Cronberg T: Clinical review: Continuous and simplified electroencephalography to monitor brain recovery after cardiac arrest. Crit Care 2013, 17:233.

38. Claassen J, Taccone FS, Horn P, Holtkamp M, Stocchetti N, Oddo M: Recommendations on the use of EEG monitoring in critically ill patients: consensus statement from the neurointensive care section of the ESICM. Intensive Care Med 2013, 39:1337-1351.

39. Cruccu G, Aminoff MJ, Curio G, Guerit JM, Kakigi R, Mauguiere F, Rossini PM, Treede RD, Garcia-Larrea L: Recommendations for the clinical use of somatosensory-evoked potentials. Clin Neurophysiol 2008, 119:1705-1719.

40. Zandbergen EG, Hijdra A, Koelman JH, Hart AA, Vos PE, Verbeek MM, de Haan RJ: Prediction of poor outcome within the first 3 days of postanoxic coma. Neurology 2006, 66:62-68.
41. Laureau E, Marciniak B, Hebrard A, Herbaux B, Guieu JD: Comparative study of propofol and midazolam effects on somatosensory evoked potentials during surgical treatment of scoliosis. Neurosurgery 1999, 45:69-74.

42. Asouhidou I, Katsaridis V, Vaidis G, loannou P, Givissis P, Christodoulou A, Georgiadis G: Somatosensory evoked potentials suppression due to remifentanil during spinal operations: a prospective clinical study. Scoliosis 2010, 5:8.

43. Robinson LR, Micklesen PJ, Tirschwell DL, Lew HL: Predictive value of somatosensory evoked potentials for awakening from coma. Crit Care Med 2003, 31:960-967.

44. Leithner C, Ploner C, Hasper D, Storm C: Does hypothermia influence the predictive value of bilateral absent N20 after cardiac arrest? Neurology 2010, 74:965-969.

45. Bender A, Howell K, Frey M, Berlis A, Naumann M, Buheitel G: Bilateral loss of cortical SSEP responses is compatible with good outcome after cardiac arrest. I Neurol 2012, 259:2481-2483.

46. Rana OR, Saygili E, Schiefer J, Marx N, Schauerte P: Biochemical markers and somatosensory evoked potentials in patients after cardiac arrest: the role of neurological outcome scores. J Neurol Sci 2011, 305:80-84.

47. Zandbergen EG, Hijdra A, de Haan RJ, van Dijk JG, Ongerboer d V, Spaans F, Tavy DL, Koelman JH: Interobserver variation in the interpretation of SSEPs in anoxic-ischaemic coma. Clin Neurophysiol 2006, 117:1529-1535.

48. Rundgren $M$, Karlsson $T$, Nielsen $N$, Cronberg $T$, Johnsson P, Friberg H: Neuron specific enolase and S-100B as predictors of outcome after cardiac arrest and induced hypothermia. Resuscitation 2009, 80:784-789.

49. Oksanen T, Tiainen M, Skrifvars MB, Varpula T, Kuitunen A, Castren M, Pettila $\checkmark$ : Predictive power of serum NSE and OHCA score regarding 6-month neurologic outcome after out-of-hospital ventricular fibrillation and therapeutic hypothermia. Resuscitation 2009, 80:165-170.

50. Fogel W, Krieger D, Veith M, Adams HP, Hund E, Storch-Hagenlocher B, Buggle F, Mathias D, Hacke W: Serum neuron-specific enolase as early predictor of outcome after cardiac arrest. Crit Care Med 1997, 25:1133-1138.

51. Steffen IG, Hasper D, Ploner CJ, Schefold JC, Dietz E, Martens F, Nee J, Krueger A, Jorres A, Storm C: Mild therapeutic hypothermia alters neuron specific enolase as an outcome predictor after resuscitation: 97 prospective hypothermia patients compared to 133 historical nonhypothermia patients. Crit Care 2010, 14:R69.

52. Daubin C, Quentin C, Allouche S, Etard O, Gaillard C, Seguin A, Valette $X$, Parienti JJ, Prevost F, Ramakers M, Terzi N, Charbonneau P, Du CD: Serum neuron-specific enolase as predictor of outcome in comatose cardiac-arrest survivors: a prospective cohort study. BMC Cardiovasc Disord 2011, 11:48.

53. Reisinger J, Hollinger $K$, Lang W, Steiner C, Winter T, Zeindlhofer E, Mori M, Schiller A, Lindorfer A, Wiesinger K, Siostrzonek P: Prediction of neurological outcome after cardiopulmonary resuscitation by serial determination of serum neuron-specific enolase. Eur Heart J 2007, 28:52-58.

54. Rosen H, Rosengren L, Herlitz J, Blomstrand C: Increased serum levels of the S-100 protein are associated with hypoxic brain damage after cardiac arrest. Stroke 1998, 29:473-477.

55. Pfeifer R, Borner A, Krack A, Sigusch HH, Surber R, Figulla HR: Outcome after cardiac arrest: predictive values and limitations of the neuroproteins neuronspecific enolase and protein S-100 and the Glasgow Coma Scale. Resuscitation 2005, 65:49-55

56. Cronberg $T$, Rundgren M, Westhall E, Englund E, Siemund R, Rosen I, Widner $H$, Friberg $H$ : Neuron-specific enolase correlates with other prognostic markers after cardiac arrest. Neurology 2011, 77:623-630.

57. Rossetti AO, Carrera E, Oddo M: Early EEG correlates of neuronal injury after brain anoxia. Neurology 2012, 78:796-802.

58. Scolletta S, Donadello K, Santonocito C, Franchi F, Taccone FS: Biomarkers as predictors of outcome after cardiac arrest. Expert Rev Clin Pharmacol 2012, 5:687-699.

59. Dankiewicz J, Linder A, Annborn M, Rundgren M, Friberg H: Heparinbinding protein: an early indicator of critical illness and predictor of outcome in cardiac arrest. Resuscitation 2013, 84:935-939.

60. Stern P, Bartos V, Uhrova J, Bezdickova D, Vanickova Z, Tichy V, Pelinkova K, Prusa R, Zima T: Performance characteristics of seven neuron-specific enolase assays. Tumour Biol 2007, 28:84-92.

61. Deakin CD, Nolan JP, Soar J, Sunde K, Koster RW, Smith GB, Perkins GD: European Resuscitation Council Guidelines for Resuscitation 2010 Section 4. Adult advanced life support. Resuscitation 2010, 81:1305-1352.

62. Inamasu J, Miyatake S, Tomioka H, Suzuki M, Nakatsukasa M, Maeda N, Ito T, Arai K, Komura M, Kase K, Kobayashi K: Subarachnoid haemorrhage as a cause of out-of-hospital cardiac arrest: a prospective computed tomography study. Resuscitation 2009, 80:977-980 
63. Chelly J, Mongardon N, Dumas F, Varenne O, Spaulding C, Vignaux O, Carli P, Charpentier J, Pene F, Chiche JD, Mira JP, Cariou A: Benefit of an early and systematic imaging procedure after cardiac arrest: insights from the PROCAT (Parisian Region Out of Hospital Cardiac Arrest) registry. Resuscitation 2012, 83:1444-1450.

64. Sugimori H, Kanna T, Yamashita K, Kuwashiro T, Yoshiura T, Zaitsu A, Hashizume M: Early findings on brain computed tomography and the prognosis of post-cardiac arrest syndrome: application of the score for stroke patients. Resuscitation 2012, 83:848-854.

65. Inamasu J, Miyatake S, Suzuki M, Nakatsukasa M, Tomioka H, Honda M, Kase K, Kobayashi K: Early CT signs in out-of-hospital cardiac arrest survivors: temporal profile and prognostic significance. Resuscitation 2010, 81:534538.

66. Metter RB, Rittenberger JC, Guyette FX, Callaway CW: Association between a quantitative $\mathrm{CT}$ scan measure of brain edema and outcome after cardiac arrest. Resuscitation 2011, 82:1180-1185.

67. Torbey MT, Geocadin R, Bhardwaj A: Brain arrest neurological outcome scale (BrANOS): predicting mortality and severe disability following cardiac arrest. Resuscitation 2004, 63:55-63.

68. Torbey MT, Selim M, Knorr J, Bigelow C, Recht L: Quantitative analysis of the loss of distinction between gray and white matter in comatose patients after cardiac arrest. Stroke 2000, 31:2163-2167.

69. Wu O, Batista LM, Lima FO, Vangel MG, Furie KL, Greer DM: Predicting clinical outcome in comatose cardiac arrest patients using early noncontrast computed tomography. Stroke 2011, 42:985-992.

70. Wijman CA, Mlynash M, Caulfield AF, Hsia AW, Eyngorn I, Bammer R, Fischbein N, Albers GW, Moseley M: Prognostic value of brain diffusionweighted imaging after cardiac arrest. Ann Neurol 2009, 65:394-402.

71. Wu O, Sorensen AG, Benner T, Singhal AB, Furie KL, Greer DM: Comatose patients with cardiac arrest: predicting clinical outcome with diffusionweighted MR imaging. Radiology 2009, 252:173-181.

72. Choi SP, Park KN, Park HK, Kim JY, Youn CS, Ahn KJ, Yim HW: Diffusionweighted magnetic resonance imaging for predicting the clinical outcome of comatose survivors after cardiac arrest: a cohort study. Crit Care 2010, 14:R17.

73. Greer DM, Scripko PD, Wu O, Edlow BL, Bartscher J, Sims JR, Camargo EE, Singhal AB, Furie KL: Hippocampal magnetic resonance imaging abnormalities in cardiac arrest are associated with poor outcome. $J$ Stroke Cerebrovasc Dis 2013, 22:899-905

74. Greer D, Scripko P, Bartscher J, Sims J, Camargo E, Singhal A, Furie K: Serial MRI changes in comatose cardiac arrest patients. Neurocrit Care 2011, 14:61-67.

75. Mlynash M, Campbell DM, Leproust EM, Fischbein NJ, Bammer R, Eyngorn I, Hsia AW, Moseley M, Wijman CA: Temporal and spatial profile of brain diffusion-weighted MRI after cardiac arrest. Stroke 2010, 41:1665-1672.

76. Kim J, Choi BS, Kim K, Jung C, Lee JH, Jo YH, Rhee JE, Kim T, Kang KW: Prognostic performance of diffusion-weighted MRI combined with NSE in comatose cardiac arrest survivors treated with mild hypothermia. Neurocrit Care 2012, 17:412-420.

77. Geocadin RG, Peberdy MA, Lazar RM: Poor survival after cardiac arrest resuscitation: a self-fulfilling prophecy or biologic destiny? Crit Care Med 2012, 40:979-980.

78. Meynaar IA, Oudemans-van Straaten HM, van der Wetering J, Verlooy $P$, Slaats EH, Bosman RJ, van der Spoel Jl, Zandstra DF: Serum neuron-specific enolase predicts outcome in post-anoxic coma: a prospective cohort study. Intensive Care Med 2003, 29:189-195.

79. Bassetti C, Bomio F, Mathis J, Hess CW: Early prognosis in coma after cardiac arrest: a prospective clinical, electrophysiological, and biochemical study of 60 patients. J Neurol Neurosurg Psychiatry 1996, 61:610-615.

80. Naatanen R, Kujala T, Kreegipuu K, Carlson S, Escera C, Baldeweg T, Ponton $\mathrm{C}$ : The mismatch negativity: an index of cognitive decline in neuropsychiatric and neurological diseases and in ageing. Brain 2011, 134:3435-3453.

81. Fischer C, Luaute J, Nemoz C, Morlet D, Kirkorian G, Mauguiere F: Improved prediction of awakening or nonawakening from severe anoxic coma using tree-based classification analysis. Crit Care Med 2006, 34:1520-1524.

82. Tzovara A, Rossetti AO, Spierer L, Grivel J, Murray MM, Oddo M, De LM: Progression of auditory discrimination based on neural decoding predicts awakening from coma. Brain 2013, 136:81-89.
83. Zandbergen EG, Koelman JH, de Haan RJ, Hijdra A: SSEPs and prognosis in postanoxic coma: only short or also long latency responses? Neurology 2006, 67:583-586.

84. Kaneko T, Kasaoka S, Miyauchi T, Fujita M, Oda Y, Tsuruta R, Maekawa T: Serum glial fibrillary acidic protein as a predictive biomarker of neurological outcome after cardiac arrest. Resuscitation 2009, 80:790-794

85. Mortberg E, Zetterberg H, Nordmark J, Blennow K, Catry C, Decraemer H, Vanmechelen E, Rubertsson S: Plasma tau protein in comatose patients after cardiac arrest treated with therapeutic hypothermia. Acta Anaesthesiol Scand 2011, 55:1132-1138.

86. Rundgren $M$, Friberg $H$, Cronberg $T$, Romner B, Petzold A: Serial soluble neurofilament heavy chain in plasma as a marker of brain injury after cardiac arrest. Crit Care 2012, 16:R45

87. Annborn M, Dankiewicz J, Erlinge D, Hertel S, Rundgren M, Smith JG, Struck $J$, Friberg $\mathrm{H}$ : Procalcitonin after cardiac arrest - an indicator of severity of illness, ischemia-reperfusion injury and outcome. Resuscitation 2013, 84:782-787.

88. Engel H, Ben HN, Portmann K, Delodder F, Suys T, Feihl F, Eggimann P, Rossetti AO, Oddo M: Serum procalcitonin as a marker of post-cardiac arrest syndrome and long-term neurological recovery, but not of early-onset infections, in comatose post-anoxic patients treated with therapeutic hypothermia. Resuscitation 2013, 84:776-781.

89. Ostadal P, Kruger A, Zdrahalova V, Janotka M, Vondrakova D, Neuzil P, Prucha M: Blood levels of copeptin on admission predict outcomes in out-of-hospital cardiac arrest survivors treated with therapeutic hypothermia. Crit Care 2012, 16:R187.

doi:10.1186/cc13696

Cite this article as: Taccone et al:: How to assess prognosis after cardiac arrest and therapeutic hypothermia. Critical Care 2014 18:202. 